\title{
Intra-amygdala injections of CREB antisense impair inhibitory avoidance memory: Role of norepinephrine and acetylcholine
}

\author{
Clinton E. Canal, ${ }^{1,4}$ Qing Chang, ${ }^{2}$ and Paul E. Gold ${ }^{1,3,5}$ \\ ${ }^{1}$ Neuroscience Program, University of Illinois, Urbana-Champaign, Illinois 61820, USA; ${ }^{2}$ Department of Animal Sciences, \\ Department of Psychology, Department of Psychiatry, Department of Biomedical Engineering, University of Illinois, \\ Urbana-Champaign, Illinois 61820, USA; ${ }^{3}$ The Institute for Genomic Biology, University of Illinois, \\ Urbana-Champaign, Illinois 61820, USA
}

\begin{abstract}
Infusions of CREB antisense into the amygdala prior to training impair memory for aversive tasks, suggesting that the antisense may interfere with CRE-mediated gene transcription and protein synthesis important for the formation of new memories within the amygdala. However, the amygdala also appears to modulate memory formation in distributed brain sites, through mechanisms that include the release of norepinephrine and acetylcholine within the amygdala. Thus, CREB antisense injections may affect memory by interfering with mechanisms of modulation, rather than storage, of memory. In the present experiment, rats received bilateral intra-amygdala infusions of CREB antisense $(2 \mathrm{nmol} / 1 \mu \mathrm{L}) 6 \mathrm{~h}$ prior to inhibitory avoidance training. In vivo microdialysis samples were collected from the right amygdala before, during, and following training. CREB antisense produced amnesia tested at $48 \mathrm{~h}$ after training. In addition, CREB antisense infusions dampened the training-related release of norepinephrine, and to a lesser extent of acetylcholine, in the amygdala. Furthermore, intra-amygdala infusions of the $\boldsymbol{\beta}$-adrenergic receptor agonist clenbuterol administered immediately after training attenuated memory impairments induced by intra-amygdala injections of CREB antisense. These findings suggest that intra-amygdala treatment with CREB antisense may affect processes involved in modulation of memory in part through interference with norepinephrine and acetylcholine neurotransmission in the amygdala.
\end{abstract}

Mechanisms within the amygdala modulate memory processing for many tasks (McGaugh 2004; Paz et al. 2006). Norepinephrine and acetylcholine are two key neurotransmitters involved in the processes by which the amygdala regulates memory formation. Stimulation or blockade of $\beta$-adrenergic norepinephrine receptors (Miranda et al. 2003; LaLumiere and McGaugh 2005) or muscarinic acetylcholine receptors (Izquierdo et al. 1992; Vazdarjanova and McGaugh 1999) in the amygdala modulate memory consolidation. In addition, avoidance training results in increased norepinephrine release in the amygdala after training (Galvez et al. 1996; Williams et al. 1998; McIntyre et al. 2002, $2003 \mathrm{~b}$ ); training-initiated release of acetylcholine is reported here. Also, blockade of $\beta$-adrenergic receptors in the amygdala prevents the memory-modulating effects of other treatments that enhance and impair memory (McGaugh 2004). Thus, these many demonstrations provide evidence for a significant role of amygdala norepinephrine and acetylcholine in memory processing.

Many findings support the view that activation of the transcription factor CREB (ㅁAMP response element-binding protein) initiates gene expression important for memory formation. For example, interference with CREB through transgenic or pharmacological manipulations leads to memory impairments, and activation of CREB is associated with the formation of memory (Dash et al. 1990; Bourtchuladze et al. 1994; Yin et al. 1994, 1995; Impey et al. 1996, 1998; Yin and Tully 1996; Guzowski and McGaugh 1997; Lamprecht et al. 1997; Silva et al. 1998; Schulz et al.

4Present address: Department of Pharmacology, Vanderbilt University School of Medicine, Nashville, TN 37232, USA.

${ }^{5}$ Corresponding author.

E-mail pgold@illinois.edu; fax (217) 244-5876.

Article is online at http://www.learnmem.org/cgi/doi/10.1101//m.904308.
1999; Pittenger et al. 2002; Barco et al. 2003; Colombo et al. 2003; Josselyn et al. 2004; Brightwell et al. 2005; Countryman et al. 2005; Josselyn and Nguyen 2005; Florian et al. 2006; Countryman and Gold 2007).

Activation of CREB in the amygdala may be important in mediating the effects on memory of norepinephrine and acetylcholine. Aversive training activates CREB in the amygdala within minutes (Stanciu et al. 2001), and disruption of CREB in the amygdala impairs memory for aversive tasks (Lamprecht et al. 1997; Josselyn et al. 2004; Ou and Gean 2007). Stimulation of $\beta$-adrenergic receptors or muscarinic receptors can induce phosphorylation of CREB (Yuan et al. 2000; Greenwood and Dragunow 2002), suggesting that norepinephrine and/or acetylcholine receptors may regulate memory functions of the amygdala through activation of CREB. There are many parallels and relationships between norepinephrine, acetylcholine, and CREB functions in the amygdala in modulation of memory processes. Treatments that impair CREB expression (Lamprecht et al. 1997; Josselyn et al. 2004) or block norepinephrine or acetylcholine function (Salinas et al. 1997; Miranda et al. 2003; Power et al. $2003 a, b)$ in the amygdala impair memory formation. Conversely, treatments that enhance CREB expression (Josselyn et al. 2001; Jasnow et al. 2005) or augment norepinephrine or acetylcholine function in the amygdala (Bianchin et al. 1999; Ferry and McGaugh 1999; Power et al. 2003a,b; LaLumiere and McGaugh 2005; McIntyre et al. 2005) near the time of training enhance the later expression of memory.

Activation of CREB in the amygdala may directly initiate the mechanisms of memory formation within the amygdala. However, given the role of the amygdala in modulating memory formation across multiple memory systems (McGaugh 2004), CREB 
may also participate in an amygdala-based neural system important for modulating memory formation elsewhere. In this way, noradrenergic and cholinergic activation of CREB in the amygdala may initiate processes in systems-level circuits that modulate subsequent experience-related release of norepinephrine and acetylcholine in the amygdala and elsewhere.

From this perspective, altering protein synthesis mechanisms in the amygdala could affect local release of neurotransmitters important for regulating memory formation (Gold 2006, 2008; Canal et al. 2007). The present experiment examined the possibility that selective interference of CREB in the amygdala may impair memory by altering training-related release of norepinephrine and/or acetylcholine in the amygdala.

\section{Results}

\section{CREB antisense infusions into the amygdala suppress} the increases in release of norepinephrine and acetylcholine in the amygdala elicited by inhibitory avoidance training

The general design of these experiments is shown in Figure 1 (top). Because neurotransmitter release was comparable in rats treated with phosphobuffered saline (PBS) and those treated with the randomized oligonucleotide sequence, the results obtained with these control treatments were combined into a single control group.

Absolute baseline (pre-training) levels of release of both norepinephrine and acetylcholine were similar in rats that had received intra-amygdala control or CREB antisense infusions 5-6 h earlier (Ps > 0.05) (Fig. 2). As shown in Figures 3 and 4, rats in all treatment groups showed significant increases in release of norepinephrine and acetylcholine in the amygdala in the sample that began with training (norepinephrine controls, $F_{(17,143)}=5.5$; norepinephrine CREB antisense, $F_{(17,161)}=3.4$; acetylcholine controls, $F_{(17,125)}=2.4$; acetylcholine CREB antisense, $F_{(17,161)}=2.9$; all $\left.P \mathrm{~s}<0.05\right)$. Post hoc tests revealed that rats that received control infusions in the amygdala $6 \mathrm{~h}$ prior to training showed significant increases in norepinephrine and acetylcholine release in the microdialysis samples taken at the time of training and in the subsequent sample after training $(P \mathrm{~s}<0.05)$, indicating increased norepinephrine and acetylcholine release in the amygdala for 8-16 min after training.

Rats that received CREB antisense infusions into the amygdala $6 \mathrm{~h}$ prior to training also showed significant increases in norepinephrine and acetylcholine release in the samples corre-
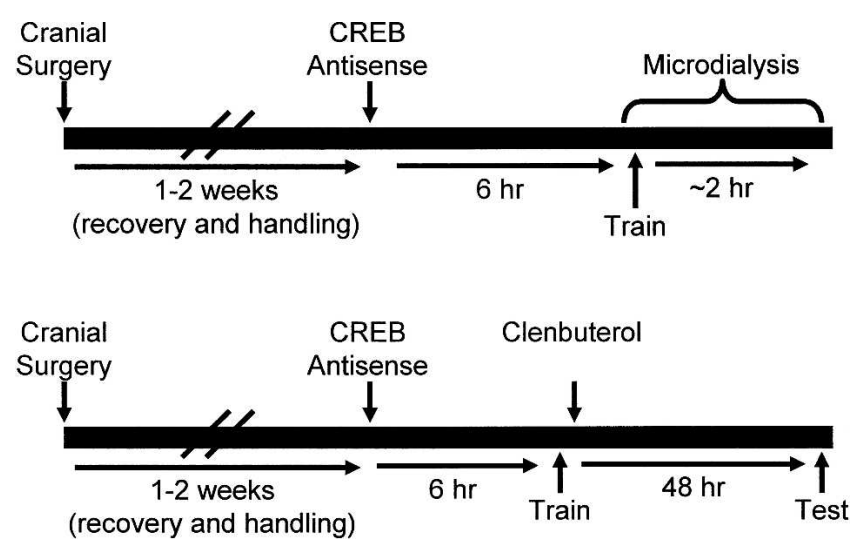

Figure 1. Experiment timelines. (Top) Design for CREB antisense and microdialysis experiment. (Bottom) Design for CREB antisense and clenbuterol effect on memory.
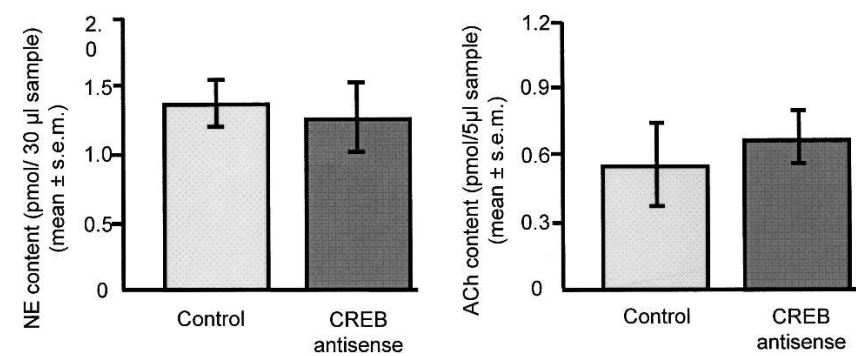

Figure 2. Baseline levels of release of norepinephrine (NE) (left) and acetylcholine (ACh) (right) in the amygdala. Note that there were no differences in baseline levels of release of either neurotransmitter following CREB antisense treatment in the amygdala.

sponding to training $(P s<0.05)$. However, in these rats treated with CREB antisense, training-related increases in norepinephrine and acetylcholine did not extend to the post-training samples $(P s>0.05)$. Therefore, the duration of training-induced release in these rats was truncated to a time within the first 8-min sample. In addition, compared to controls, rats that received CREB antisense infusions into the amygdala showed decreased peaks in training-related release of norepinephrine in the amygdala $\left(F_{(1,195)}=5.61, P<0.05\right)$; CREB antisense significantly suppressed peak percent increases in norepinephrine levels corresponding to training, and in post-training samples corresponding to $24-32 \mathrm{~min}$ after training $(P \mathrm{~s}<0.05)$. However, there were no significant differences between amygdala control and CREB antisense-treated rats in the peak release of acetylcholine in the amygdala after training $\left(F_{(1,182)}=1.52, P>0.05\right)$.

Rats in this microdialysis experiment treated with CREB antisense also showed impaired memory of inhibitory avoidance 48 $\mathrm{h}$ after training relative to controls (data not shown), similar to the results of the behavioral experiment described next.

\section{CREB antisense-induced impairments in 48-h memory are attenuated by post-training intra-amygdala} injections of clenbuterol

In the absence of treatment with CREB antisense, immediate post-training infusions of $10 \mathrm{ng}$ of clenbuterol into the amygdala resulted in inhibitory avoidance latencies significantly higher than those of saline controls as tested $48 \mathrm{~h}$ after training $(P<0.05)$ (Fig. 5).

Figure 6 illustrates the effects on inhibitory avoidance scores of CREB antisense with and without coadministration of clenbuterol. The general experimental design is described in Figure 1

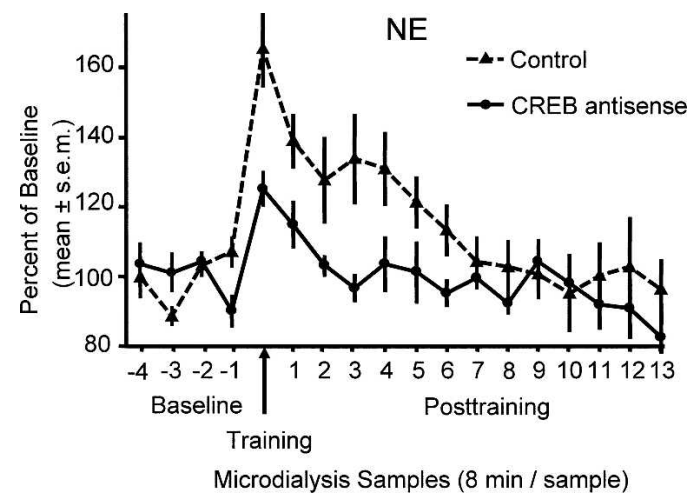

Figure 3. Increases in release of norepinephrine (NE) in the amygdala after inhibitory avoidance training. Note that training resulted in increased release of NE in both controls and CREB antisense groups. However, the magnitude and duration of release was reduced in rats treated with CREB antisense. 


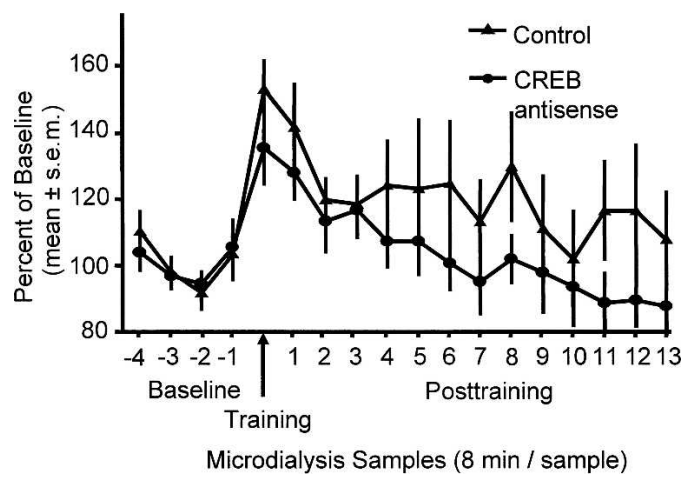

Figure 4. Increases in release of acetylcholine (ACh) in the amygdala after inhibitory avoidance training. Note that training resulted in increased release of $\mathrm{ACh}$ in both controls and CREB antisense groups. Also, the duration but not initial magnitude of release was attenuated in rats treated with CREB antisense.

(bottom). When tested $48 \mathrm{~h}$ after training, rats that received intra-amygdala CREB antisense $6 \mathrm{~h}$ before training had latencies significantly lower than those of rats that received rOGN infusions $(P<0.05)$. An immediate post-training infusion of clenbuterol into the amygdala significantly reversed the effect of the antisense $\left(F_{(3,22)}=4.1 ; P<0.05\right)$, increasing latencies to values comparable to those of controls. The attenuation of antisenseinduced impairments of memory by clenbuterol was dosedependent, with attenuation evident at the 10-ng dose $(P<0.05)$ but not the 1-ng dose $(P>0.05)$.

\section{Intra-amygdala CREB antisense resulted in decreased expression of CREB and $\mathrm{PCREB}$}

Unilateral injections of CREB antisense into the amygdala $6 \mathrm{~h}$ before training decreased expression of CREB and pCREB assessed $45 \mathrm{~min}$ after training. The antisense injections resulted in $21 \%$ and 25\% decreases in CREB and pCREB expression, respectively, as compared to contralateral measures after PBS injections. All rats had reduced CREB and PCREB expression on the side that received antisense injections compared to the contralateral PBSinjected side; the decreases in CREB and pCREB expression were both statistically significant (paired $t$-tests, $P \mathrm{~s}<0.05$ ). Examples of the differential expression of CREB and PCREB on antisense and control sides of the amygdala are shown in Figure 7.

\section{Intra-amygdala CREB antisense suppressed} training-related expression of c-Fos in the amygdala A unilateral injection of CREB antisense into the amygdala $6 \mathrm{~h}$ prior to training suppressed the training-related increase in c-Fos

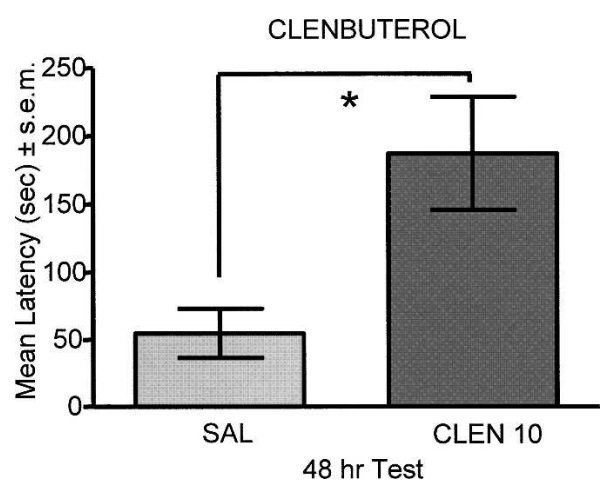

Figure 5. Effects of intra-amygdala injections of clenbuterol on memory. Immediate post-training injections of clenbuterol $(10 \mathrm{ng})$ significantly enhanced memory assessed $48 \mathrm{~h}$ after training. $\left(^{*}\right) P<0.05$.

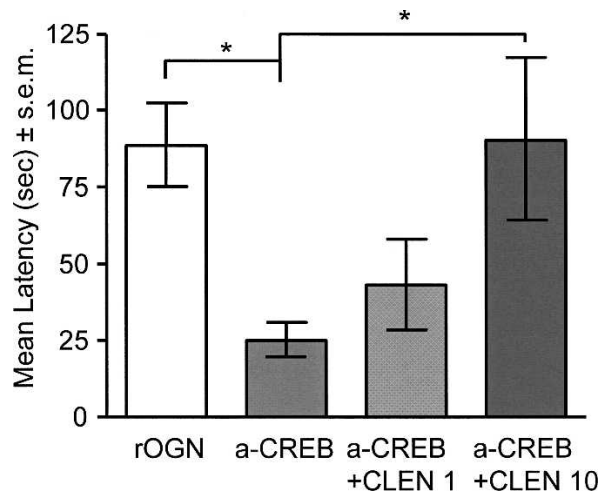

Figure 6. Effects of intra-amygdala injections of CREB antisense and clenbuterol on memory. CREB antisense injections $6 \mathrm{~h}$ prior to training resulted in significantly lower latencies on memory tests $48 \mathrm{~h}$ after training (rOGN vs. a-CREB). Immediate post-training injections of clenbuterol, at a 10-ng but not a 1-ng dose, into the amygdala attenuated the effects of CREB antisense (a-CREB vs. a-CREB + CLEN 10). (rOGN) Randomized oligodeoxynucleotide; (a-CREB) CREB antisense; (CLEN 1) clenbuterol, 1 ng; (CLEN 10) clenbuterol, 10 ng; $\left(^{*}\right) P<0.05$.

on that side relative to a control PBS contralateral injection. An example of the differential expression of post-training c-Fos in the lateral amygdala ipsilateral and contralateral to the injection of CREB antisense is shown in Figure 8. This example is consistent with the quantification of cell counts, in which training-
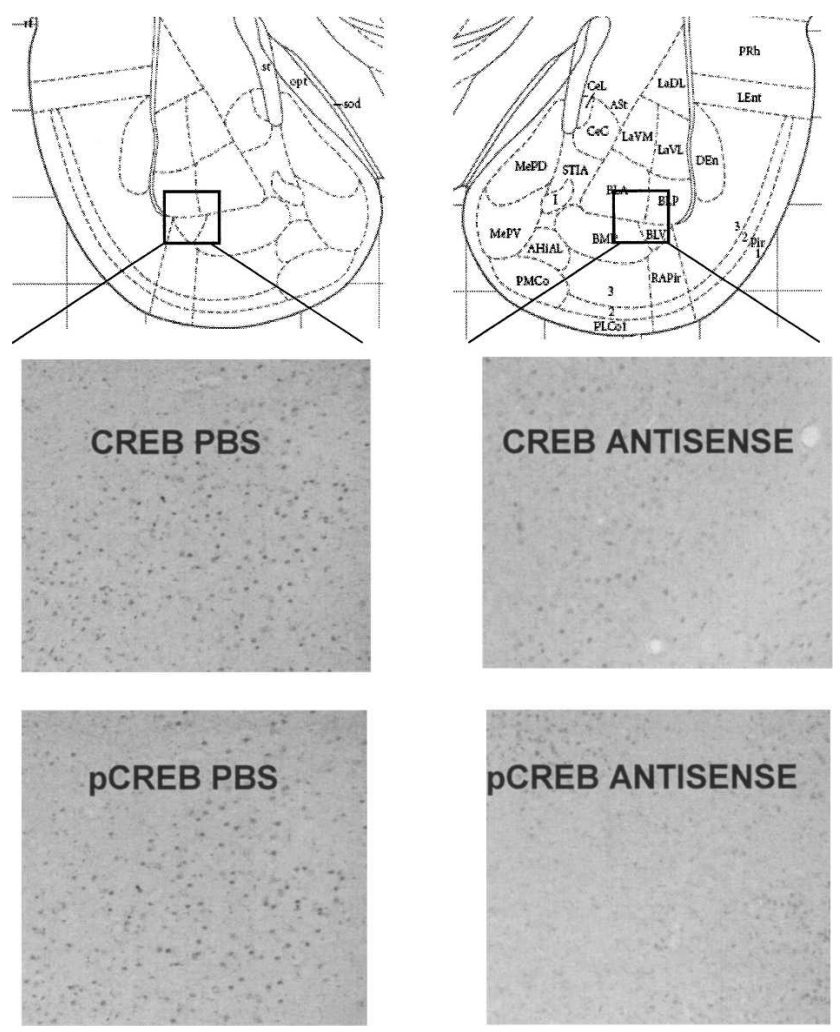

Figure 7. Expression of CREB and $P C R E B$ in the amygdala after CREB antisense or PBS control injections into opposite sides of the amygdala 6 $\mathrm{h}$ prior to training. Brains were collected $45 \mathrm{~min}$ after training. Sections shown are $\sim 100 \mu \mathrm{m}$ posterior to the infusion sites. Note that expression of both CREB and PCREB was depressed in the antisense versus control side. The Atlas figures are adapted from Paxinos and Watson (2005) (reprinted with permission from Elsevier @2005). Bregma -3.24. 


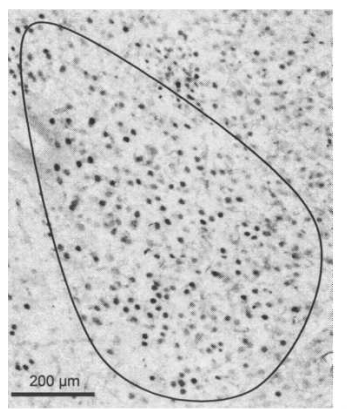

Control

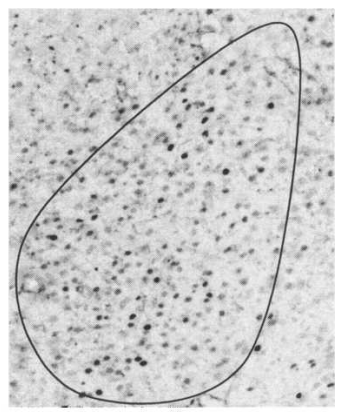

CREB antisense
Figure 8. Expression of $\mathrm{c}$-Fos after CREB antisense or PBS control injections into opposite sides of the amygdala $6 \mathrm{~h}$ prior to training. Brains were collected 90 min after training. Sections shown are $\sim 100 \mu \mathrm{m}$ rostral to the infusion sites. Note the decreased c-Fos expression in the lateral amygdala (outlined) on the antisense-injected versus control side of the amygdala.

related expression of c-Fos in the amygdala in antisense-treated rats was 33\% less than that of controls (Fig. 9). All rats had reduced c-Fos expression on the side of antisense injection versus the side of control injection (paired $t$-test, $P<0.05$ ).

\section{Injections were in the basolateral and lateral amygdala}

A representative placement of a guide cannula with a microinjection needle extending below the guide is shown in Figure 10. Injection sites for all animals included in data analyses were within the basolateral and lateral nuclei of the amygdala.

\section{Discussion}

The findings of the present experiments indicate that pretreatment with CREB antisense injections into the amygdala $6 \mathrm{~h}$ before training result in impaired memory tested $48 \mathrm{~h}$ after training. The injections decreased the expression of CREB and pCREB at $45 \mathrm{~min}$ after training and also decreased the training-related expression of c-Fos as measured $90 \mathrm{~min}$ after training. In addition to these effects, treatment with CREB antisense also resulted in diminished release of norepinephrine and acetylcholine in response to training. Post-training injections of the $\beta$-adrenergic agonist clenbuterol attenuated the amnesia induced by prior antisense treatment.

CREB activation in the amygdala occurs after fear and avoidance training and retrieval (Davies et al. 2004; Saha and Datta 2005; Ou and Gean 2007). The finding that CREB antisense injections into the amygdala impair memory is consistent with past evidence showing that antisense and other treatments that impair CREB expression in the amygdala also impair memory

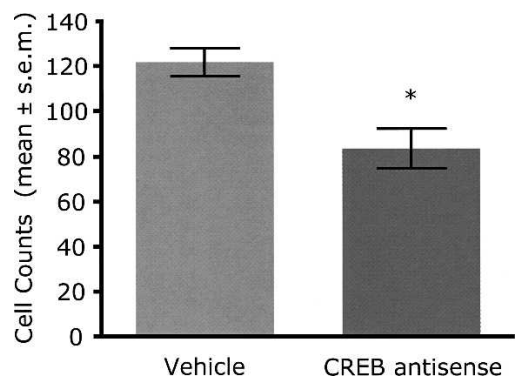

Figure 9. C-Fos protein expression $6 \mathrm{~h}$ after intra-amygdala infusions of control or CREB antisense, and $1.5 \mathrm{~h}$ after inhibitory avoidance training. Note the decreased expression of c-Fos protein in the lateral amygdala following CREB antisense treatment; $\left({ }^{*}\right) P<0.05$.
(Lamprecht et al. 1997; Davies et al. 2004; Josselyn et al. 2004; Ou and Gean 2007). Conversely, enhanced memory has been observed under conditions that augment CREB activation (Josselyn et al. 2001; Jasnow et al. 2005). Thus, the present findings are consistent with findings that up-regulation and down-regulation of CREB in the amygdala can alter memory processing.

It is noteworthy that the present findings indicate that CREB and pCREB levels in the amygdala decreased only modestly, by $\sim 20 \%-25 \%$ on the antisense-injected versus controlinjected side. To avoid damaged tissue, the measures were taken $\sim 100 \mu \mathrm{m}$ away from the cannulae tracks and therefore likely underestimated the reduction at sites more proximal to the injection itself. Nonetheless, the values obtained here are only slightly lower than the $30 \%-40 \%$ decreases in CREB protein levels reported by others (e.g., Guzowski and McGaugh 1997; Choi et al. 2006) and indicate that some CREB protein remained available for activation at the time of training. The magnitude of the decreases in CREB expression are generally consistent with the 33\% decreases in c-Fos expression, used here as a measure of protein expression initiated by training (e.g., Radulovic et al. 1998; Savonenko et al. 1999; Holahan and White 2004).

In the present experiment, we also examined release of acetylcholine and norepinephrine in control and antisense-treated rats. Both acetylcholine and norepinephrine were released in the amygdala in response to training in control rats. The increase in norepinephrine release after inhibitory avoidance training has been reported before (Galvez et al. 1996; Williams et al. 1998), and the magnitude of the increase in norepinephrine release in the amygdala after training was correlated positively with later memory scores (McIntyre et al. 2002). To our knowledge, the response of acetylcholine release to inhibitory avoidance training has not been reported before, although increases in release of acetylcholine in the amygdala have been reported during feeding (Hajnal et al. 1998) and after tail-shock (Mark et al. 1996), as well as during spontaneous alternation testing where the magnitude of release was correlated positively with working memory scores (McIntyre et al. 2003a).

Of particular interest in the present set of experiments, CREB antisense infusions into the amygdala $6 \mathrm{~h}$ before training dampened the training-related increases of both norepinephrine and acetylcholine in the amygdala. The training-related release of both norepinephrine and acetylcholine in the amygdala was abbreviated in rats that had received CREB antisense. In addition, rats that received CREB antisense showed smaller peak increases in norepinephrine release in the amygdala after inhibitory avoidance training.

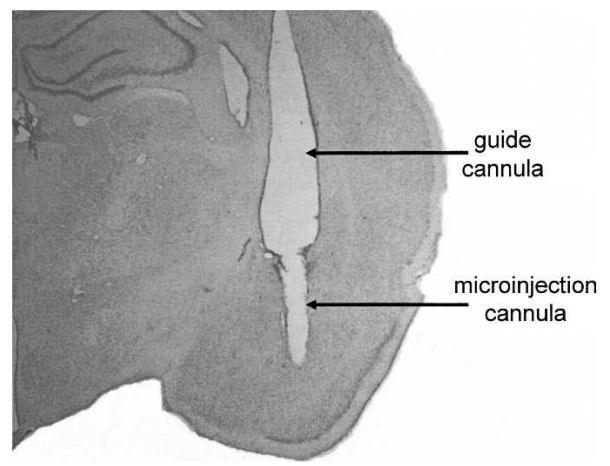

Figure 10. Representative photomicrograph showing guide cannula placement dorsal to the amygdala and microinjection cannula placement in the amygdala. Microinjections were administered bilaterally, and microdialysis samples were collected from the right amygdala. 
Linking the diminished norepinephrine response to impaired memory, post-training injections of the $\beta$-adrenergic receptor agonist clenbuterol directly into the amygdala attenuated the memory impairment in rats that had received CREB antisense injections in to the amygdala $6 \mathrm{~h}$ earlier. As seen previously (Ferry and McGaugh 1999; LaLumiere and McGaugh 2005; McIntyre et al. 2005; cf. McGaugh 2004), clenbuterol was an effective memory-enhancing treatment when injected into the amygdala in control rats. These results are consistent with demonstrations that intra-amygdala injections of norepinephrine enhance memory (Liang et al. 1990, 1995; Hatfield and McGaugh 1999; Berlau and McGaugh 2006), and intra-amygdala injections of $\beta$-adrenergic receptor antagonists impair memory (Gallagher et al. 1977; Gallagher and Kapp 1981) and block modulation of memory by many treatments (Liang et al. 1986; Berlau and McGaugh 2006; cf. McGaugh 2004).

Also related to the present findings is evidence that the memory impairments observed in CREB mutant mice can be rescued by treatment at the time of training with epinephrine (Frankland et al. 2004). Epinephrine is a well-studied hormone that enhances memory (McIntyre et al. 2003b; Gold 2005; Roozendaal et al. 2008). The central mechanisms by which epinephrine enhances memory appear to include stimulation of the release of norepinephrine in the amygdala (Gold and van Buskirk 1978a,b; Williams et al. 1998). The attenuation by epinephrine of memory impairments in CREB knockout mice may reflect activation of residual CREB by $\beta$-adrenergic receptor actions within the amygdala and elsewhere. Thus, the results of these experiments and those presented here suggest that norepinephrine and CREB in the amygdala may be interacting components of a neurobiological mechanism that regulates memory formation.

The neurochemical findings open the possibility that CREB antisense injections into the amygdala might impair memory by disrupting learning-induced release of norepinephrine and acetylcholine in the amygdala. This interpretation contrasts with a more typical view in which findings that interference with CREB functions produces memory impairments are often taken as support for the view that the flow of information from extracellular signals to intracellular signals and genomic responses initiate and comprise the molecular bases of memory formation (e.g., Lamprecht et al. 1997; Zhang et al. 2003; Florian et al. 2006; cf. Kandel 2001; Schafe et al. 2001; Selcher et al. 2002; Josselyn et al. 2004). The alternative suggested by the present results is that manipulations of CREB functions may have neurobiological effects that lead to altered neurotransmitter release, and that the disrupted patterns of neuronal communication may produce the impairments of memory.

The interpretation that neurotransmitter functions might mediate amnesia after CREB antisense treatment is consistent with recent findings that intra-amygdala injections of anisomycin inhibited protein synthesis, produced amnesia, and also resulted in substantial increases and decreases in release of norepinephrine, as well as dopamine and serotonin, at the site of injection (Canal et al. 2007; cf. Gold 2008). Also, amnesia produced by anisomycin injections was attenuated by intra-amygdala administration of a $\beta$-adrenergic antagonist, propranolol, prior to the peak release of norepinephrine and by a $\beta$-adrenergic agonist, clenbuterol, at the time of the lowest levels of norepinephrine release. The design in this earlier experiment involved anisomycin injections within $1 \mathrm{~h}$ of training and measures of neurotransmitter release before and after injection and training. In the present experiment, the CREB antisense injections were made $6 \mathrm{~h}$ prior to training and $5 \mathrm{~h}$ prior to the first NE and ACh measures. Therefore, the present findings do not reveal acute effects of the antisense on release of neurotransmitters, effects that should be assessed in future experiments. At the times tested in the present experiment, the findings do, however, indicate that neurotransmitter release in response to training is impaired and suggest that CREB antisense, like anisomycin, leads to disruption in neurotransmitter functions that may mediate amnesia.

Note that CREB antisense is expected to inhibit protein synthesis, although in a far more restricted manner than is the case with anisomycin. Across these experiments, it appears that inhibition of protein synthesis may be a common mediator of abnormal neurotransmitter release profiles. The findings therefore suggest that treatments that interfere with training-related protein expression, thus far including CREB antisense and anisomycin, may produce amnesia by blocking protein synthesis with consequent disruption of cell-cell signaling in the amygdala.

Because the norepinephrine cell bodies that provide the neurotransmitter to the amygdala are located outside the amygdala (Aston-Jones 2004), it is unlikely that CREB antisense acted directly on nuclear gene expression in noradrenergic cells that project to the amygdala. Similarly, much of the acetylcholine comes from projection neurons, mainly from the basal forebrain (Woolf and Butcher 1982; Carlson et al. 1985). However, it is worth noting that there are also small local circuit cholinergic neurons in the basolateral amygdala (Carlson and Heimer 1986) that may participate in modulation of memory (Power et al. 2003a) and may be targets of CREB antisense.

The altered training release of norepinephrine and acetylcholine after CREB antisense treatment may reflect altered neural activity of amygdala neurons with local pre-synaptic control of norepinephrine or acetylcholine release by glutamate, as seen in other brain regions (cf. Raiteri 2006, 2008). Alternatively, it is possible that CREB antisense interfered with normal functions of neurons within the amygdala, leading, in turn, to altered neural activity in other associated neural systems with projections back to the amygdala. For example, the amygdala has direct projections to basal forebrain cholinergic neurons (Amaral et al. 1992) and to noradrenergic cell bodies in the locus coeruleus (Wallace et al. 1992). The anatomical relationships of the amygdala with neurotransmitter systems that modulate memory formation suggest that CREB antisense treatment in the amygdala might suppress training-related release of norepinephrine and acetylcholine in the amygdala by affecting neurons projecting from the amygdala to the source neurons for these neurotransmitters.

It is important to note too that, as with protein synthesis inhibitors, antisense oligonucleotides may have effects beyond those of their intended specificity. In particular, while fully phosphorothioated antisense oligonucleotides, as used here, have good stability because of resistance to nucleases, they also often exhibit toxic side effects in many tissues (e.g., Giles and Tidd 1992; Ehrlich et al. 1994; Hebb and Robertson 1997; Qiao et al. 2003; cf. Levin 1999; Kurreck 2003) and when injected into brain can alter baseline neurophysiology in the hippocampus (Guzowski et al. 2000). These side effects may contribute to antisense effects on memory but also to the neurochemical results presented here. Specifically, the neurochemical effects may reflect neural responses to toxicity or to altered neurophysiology separate from effects mediated by knockdown of CREB per se.

In summary, the findings of this experiment indicate that, while impairing memory formation, injections of CREB antisense into the amygdala also result in blunting of training-related increases in local release of norepinephrine and acetylcholine. The antisense-induced decreases in neurotransmitter function may contribute to the memory impairments, supporting the possibility that CREB may participate in modulating memory formation by regulating neurotransmitter release instead of, or in addition to, initiating patterns of protein synthesis intrinsic to the formation of new memories. 


\section{Materials and Methods}

\section{Animals}

Adult male, Sprague-Dawley rats (3 mo old; Harlan Laboratories) were used as test subjects. Each rat was individually housed in a plastic cage with ad libitum access to food and water in a temperature- and humidity-controlled vivarium and maintained on a 12:12 lights on/off cycle.

\section{Surgery}

For the microinjection plus microdialysis experiments, rats were anesthetized with sodium pentobarbital $(50 \mathrm{mg} / \mathrm{kg}$, i.p., plus supplements as needed). Rats were positioned in a stereotaxic apparatus with skulls in a horizontal orientation. One stainlesssteel guide cannula (22 gauge; Plastics One Inc.) was implanted 2 $\mathrm{mm}$ above the left amygdala, and one microdialysis guide cannula (CMA/12; Carnegie Medicin) was implanted $2 \mathrm{~mm}$ above the right amygdala (from bregma: $3.2 \mathrm{~mm}$ posterior, $4.8 \mathrm{~mm}$ lateral, and $5.8 \mathrm{~mm}$ ventral to the surface of the skull).

For the microinjection experiments, guide cannulae (23 gauge; Plastics One Inc.) were implanted bilaterally to a position $2 \mathrm{~mm}$ above the amygdala (from bregma: $2.9 \mathrm{~mm}$ posterior, 4.8 lateral, 5.0 ventral to dura) under $2 \%$ isoflurane anesthesia. The guide cannulae were anchored in place with dental cement and skull screws. Stylets flush with the guide cannulae tips were secured inside the guide cannulae to maintain patency. Following recovery from surgery for $\sim 1 \mathrm{wk}$, rats were handled daily until the start of experimental manipulations. Figure 1 shows experiment timelines for procedures in the antisense-microdialysis (panel A) and antisense-clenbuterol (panel B) experiments.

\section{Drugs}

CREB antisense and randomized oligodeoxynucleotide control (rOGN) were synthesized by Biognostik (Germany). The CREB antisense, sequence 5'-GTCCATGGTCATCTAGTC-3', was fully phosphorothioated and targeted region $34-51$ bases of the total sequence and overlapped the start codon of rat CREB. The rOGN consisted of a fully phosphorothioated scrambled sequence of oligodeoxynucleotides of equal length to the antisense, yet with no significant affinity for mammalian mRNA (NCBI GenBank; Biognostik). Both the antisense and rOGN were suspended in $1 \times$ PBS (Biognostik) prior to microinjections. Clenbuterol hydrochloride (Sigma) was dissolved in sterile 0.9\% saline.

\section{Intra-amygdala microinjections}

For the combined microinjection-microdialysis experiments, an infusion needle (28 gauge; Plastics One Inc.) was inserted into the guide cannulae implanted in the left amygdala, extending $2 \mathrm{~mm}$ beyond the pedestal of the guide cannula. A CMA/12 probe ( 2 $\mathrm{mm}$; Carnegie Medicin) adapted for microinjection was inserted into the microdialysis guide cannula. The infusion needles were connected by polyethylene tubing to $25-\mu \mathrm{L}$ microsyringes, which were secured on a CMA/100 microinjection pump (Carnegie Medicin). Six hours prior to training, CREB antisense (2 nmol/ $1 \mu \mathrm{L}$ PBS; $1 \mu \mathrm{L}$ infused over 2 min) was infused bilaterally into the amygdala. Previous findings suggest that $6 \mathrm{~h}$ is sufficient time to allow run-down of CREB prior to training and to impair new memory formation (Guzowski and McGaugh 1997; Zhang et al. 2003). The control group received either rOGN $(2 \mathrm{nmol} / 1 \mu \mathrm{L})$ or PBS $(1 \mu \mathrm{L})$ infusions into the amygdala $6 \mathrm{~h}$ prior to training. The infusion cannulae were left in place for an additional $1 \mathrm{~min}$ to allow diffusion of the solution away from the cannulae tips.

Diffusion of the antisense in the amygdala was likely not limited to a restricted set of nuclei in the amygdala but probably included much of the amygdala, with limited diffusion across the barriers of the corpus callosum and optic tract. The diffusion of drugs after intracerebral injection is difficult to discern, varying with time after injection, physical barriers such as fiber tracts, location of injection, and concentration and volume of injection. Moreover, the apparent locus of function action varies widely with the measure used to identify the affected region
(Caine et al. 1995; Edeline et al. 2002; see also additional references in Edeline et al. 2002).

Rats received bilateral intra-amygdala microinjections of CREB antisense ( $N=9$ for norepinephrine sampling; $N=9$ for acetylcholine sampling), rOGN ( $N=5$ for norepinephrine sampling; $N=3$ for acetylcholine sampling), or PBS ( $N=3$ for norepinephrine sampling; $N=4$ for acetylcholine sampling).

Procedures for the microinjection-memory experiments were similar to those of the microdialysis experiments with the exception that all drugs were infused bilaterally at a rate of 0.125 $\mu \mathrm{L} / \mathrm{min}$ through the infusion cannulae (30 gauge; Plastics One Inc.). One set of rats received intra-amygdala injections of the $\beta$-adrenergic receptor agonist clenbuterol $(10 \mathrm{ng} / 0.2 \mu \mathrm{L}$ saline, $N=10)$ or saline $(0.2 \mu \mathrm{L}, N=9)$ immediately after inhibitory avoidance training (footshock $=0.5 \mathrm{~mA} / 1 \mathrm{sec}$ ). A second set of rats received intra-amygdala CREB antisense $(2 \mathrm{nmol} / \mu \mathrm{L} \mathrm{PBS})$ or rOGN ( $2 \mathrm{nmol} / \mu \mathrm{L}$ PBS) $6 \mathrm{~h}$ prior to inhibitory avoidance training (footshock $=0.5 \mathrm{~mA} / 1.5 \mathrm{sec}$ ). Immediately after training, rats received intra-amygdala infusions of either clenbuterol (1 or 10 $\mathrm{ng} / 0.2 \mu \mathrm{L})$, saline $(0.2 \mu \mathrm{L})$, or no treatment. The groups thus included CREB antisense/clenbuterol, $1 \mathrm{ng}(N=6)$; CREB antisense/clenbuterol, $10 \mathrm{ng}(N=5)$; CREB antisense/saline $(N=2)$; CREB antisense/no treatment $(N=4)$; rOGN/saline $(N=4)$; or rOGN/no treatment $(N=2)$. CREB antisense/saline and CREB antisense/no treatment groups were combined for the statistical analyses; the the rOGN/saline and rOGN/no treatment groups were similarly combined.

\section{Microdialysis}

Four hours after antisense or control infusions, a 2-mm probe (CMA/12; Carnegie Medicine) was inserted into the right amygdala. After probe insertion, each rat was placed in a holding chamber $(\sim 30 \times 30 \times 41 \mathrm{~cm}, \mathrm{l} \times \mathrm{w} \times \mathrm{h})$ that contained fresh bedding. For norepinephrine sampling, the dialysis probes were perfused continuously at a rate of $3.0 \mu \mathrm{L} / \mathrm{min}$ with artificial cerebrospinal fluid (aCSF, $128 \mathrm{mM} \mathrm{NaCl}, 2.5 \mathrm{mM} \mathrm{KCl}, 1.3 \mathrm{mM}$ $\mathrm{CaCl}_{2}, 2.1 \mathrm{mM} \mathrm{MgCl}_{2}, 0.9 \mathrm{mM} \mathrm{NaH}_{2} \mathrm{PO}_{4}, 2.0 \mathrm{mM} \mathrm{Na}_{2} \mathrm{HPO}_{4}$, and $1.0 \mathrm{mM}$ dextrose, adjusted to $\mathrm{pH}$ 7.4). To allow equilibration with brain extracellular fluid and to avoid temporary changes in extracellular neurotransmitter levels caused by acute tissue damage (Westerink and Timmerman 1999), the first hour of dialysate was discarded. Samples collected during the subsequent hour, from 5 to $6 \mathrm{~h}$ after antisense injections, served as pre-training baselines. The time for each sample collection was $8 \mathrm{~min}$. Thus, each sample contained $24 \mu \mathrm{L}$ of dialysate, which was collected into a vial containing $12 \mu \mathrm{L}$ of $0.2 \mathrm{M}$ acetic acid.

For acetylcholine sampling $(8 \mathrm{~min}, 1 \mu \mathrm{L} / \mathrm{min})$, the microdialysis procedure was similar to that of norepinephrine, but the aCSF contained $200 \mathrm{nM}$ neostigmine, an acetylcholinesterase inhibitor. In addition to increasing the acetylcholine content in samples, low concentrations of neostigmine in the microdialysis perfusate are also needed to allow detection of training-related changes in acetylcholine release in the brain (Chang et al. 2006). For both norepinephrine and acetylcholine sampling, four baseline samples were collected before rats were trained on inhibitory avoidance, and 14 post-training samples were then collected while rats remained in the holding chamber. Samples were sealed and stored at $-80^{\circ} \mathrm{C}$ for later measurement of norepinephrine or acetylcholine content.

\section{Inhibitory avoidance training and testing}

Six hours after intra-amygdala CREB antisense or control infusions, rats were trained on an inhibitory avoidance task. The apparatus was a trough-shaped alley $(91 \mathrm{~cm}$ length, $22.9 \mathrm{~cm}$ width at the top, $\times 7.6 \mathrm{~cm}$ width at the bottom, $15.2 \mathrm{~cm}$ depth) divided into lit $(31 \mathrm{~cm})$ and dark $(60 \mathrm{~cm})$ compartments by a door that could be lowered and raised through the floor. The floor and walls consisted of stainless-steel plates through which footshock could be administered. Rats were placed into the lit 
start compartment and, $20 \mathrm{sec}$ later, the door was lowered. After rats crossed into the dark compartment, the door was raised, and a brief footshock was administered. In the CREB antisense experiments, a footshock of $0.5 \mathrm{~mA} / 1 \mathrm{sec}$ was used to avoid a floor effect. In the studies of clenbuterol enhancement of memory in the absence of CREB antisense treatment, the footshock level was lowered slightly to $0.45 \mathrm{~mA} / 1 \mathrm{sec}$ to avoid possible ceiling effects. Rats were removed from the apparatus within $15 \mathrm{sec}$ after footshock. Forty-eight hours after training, rats were returned to the lighted compartment of the inhibitory avoidance apparatus, the door was lowered, and latencies to cross into the dark compartment were recorded as the index of memory.

\section{Norepinephrine assay}

Microdialysis samples collected from the amygdala were assayed for norepinephrine using HPLC plus electrochemical detection. The mobile phase $\left(100 \mathrm{mM} \mathrm{NaH}{ }_{2} \mathrm{PO}_{4}, 130 \mu \mathrm{M}\right.$ EDTA, $260 \mu \mathrm{M}$ octane sulfonic acid, 3.5\% acetonitrile [v/v], 2.0\% methanol $[\mathrm{v} / \mathrm{v}]$, and $0.01 \%$ triethylamine $[\mathrm{v} / \mathrm{v}]$ at $\mathrm{pH} 3.1$ ) was driven by a solvent delivery system (ESA 580 pump; ESA Inc.) at a rate of 0.7 $\mathrm{mL} / \mathrm{min}$. Samples were automatically injected by a Waters 717 Plus auto-injector (Waters). Norepinephrine was separated by an ODS C18 reverse phase analytical column (HR-80, 3 micron, $100 \times 3.2 \mathrm{~mm}$; ESA Inc.). Electrochemical detection was performed by an ESA Coulochem III detector with a Model 5014B analysis cell (ESA Inc.). The working potentials were set at -150 $\mathrm{mV}$ for electrode I, $+220 \mathrm{mV}$ for electrode II and $+280 \mathrm{mV}$ for the guard cell. Norepinephrine peaks were quantified by comparison of peak areas from microdialysis samples to peak areas of standards with known norepinephrine concentrations after adjustments for probe efficiencies. The detection limit of this system was determined to be $\sim 6 \mathrm{fmol}$ ( $\sim 1 \mathrm{pg}$ ) for norepinephrine.

\section{Acetylcholine assay}

In a separate set of rats, microdialysis samples collected from the amygdala were assayed for acetylcholine by HPLC with electrochemical detection (Bioanalytical Systems Inc. [BAS]). The assay system included an ion-exchange microbore analytical column (BAS), a microbore acetylcholine/choline immobilized enzyme reactor (IMER) containing acetylcholinesterase and choline oxidase (BAS), an auxiliary electrode with radical flow electrochemical thin-layer cell and $13 \mathrm{~mm}$ thin-layer gasket, a "wired" enzyme electrode kit (a redox polymer film containing horseradish peroxidase coated on the surface of a $6 \mathrm{~mm}$ glass/carbon working electrode; BAS), and a low-dispersion injection valve with a $10-\mu \mathrm{L}$ polyether ether ketone loop (Rheodyne model 9725i). The mobile phase $\left(50 \mathrm{mM} \mathrm{Na}_{2} \mathrm{HPO}_{4}\right.$ at $\mathrm{pH} 8.5$ and $0.005 \%$ ProClinTM 150 microbiocide [BAS], $140 \mu \mathrm{L} / \mathrm{min}$ ) was generated by a Shimadzu LC-10ADvp pump with micro-step plunger (Shimadzu Scientific Instruments). The potential held by the working electrode was $100 \mathrm{mV}$ versus a $\mathrm{Ag} / \mathrm{AgCl}$ reference electrode. The injection volume in this experiment was $5.0 \mu \mathrm{L}$ per sample. The detection limit was $\sim 5 \mathrm{fmol}(\sim 0.7 \mathrm{pg})$.

\section{Cannulae placement histology}

Following testing, rats received an overdose of pentobarbital and were perfused intracardially with sterile $0.9 \%$ saline followed by freshly prepared $4 \%$ paraformaldehyde $/ 0.1 \mathrm{M}$ phosphate buffer. Brains were removed and later post-fixed in $4 \%$ paraformaldehyde for $\sim 24 \mathrm{~h}$ at $4^{\circ} \mathrm{C}$. Brains were cryoprotected in $20 \%$ glycerol/ $0.1 \mathrm{M}$ phosphate buffer for $\sim 48 \mathrm{~h}$ and then sectioned on a cryostat (Leica) at $50 \mu \mathrm{m}$. Sections that traversed the infusion sites were collected, mounted on glass slides, and stained with cresyl violet. Data from rats with misplaced cannulae were not included in the data analyses.

\section{CREB and $\mathrm{pCREB}$ expression}

CREB antisense $(2 \mathrm{nmol} / 1 \mu \mathrm{L})$ was infused into one amygdala, and PBS $(1 \mu \mathrm{L})$ was infused into the contralateral amygdala $6 \mathrm{~h}$ prior to inhibitory avoidance training $(0.5 \mathrm{~mA} / 1.5 \mathrm{sec})$. Rats $(N=5)$ were anesthetized $45 \mathrm{~min}$ later, and brains were sectioned on a cryostat. Sections to be analyzed were taken $\sim 100 \mu \mathrm{m}$ posterior to the cannulae tracks. This procedure enabled cell counts in intact tissue, thereby avoiding effects secondary to the lesion and infusion per se. The trade-off, however, is that the tissue most proximal to the injection, and presumably with greater reduction in expression, was not measured. Free-floating sections were washed in PBS, followed by incubation in $0.5 \% \mathrm{H}_{2} \mathrm{O}_{2}$ for 20 $\mathrm{min}$. The sections were washed in PBS again and then incubated in blocking solution containing $10 \%$ normal goat serum, $2 \%$ bovine serum albumin, and $0.1 \%$ Triton $\mathrm{X}$ in PBS. The sections were then incubated in primary antibody (1:8000 CREB polyclonal antibody [Cell Signaling], or 1:2000 pCREB polyclonal antibody [Upstate Cell Signaling Solution-Millipore]) overnight at room temperature. The sections were then washed in PBS, followed by a 1-h incubation in secondary antibody (1:400 goat anti-rabbit; Santa Cruz Biotechnology). The sections were again washed in PBS and then immunostained using the ABC Vectastain Elite kit (Vector Laboratories) and 3,3'-diaminobenzidine peroxidase substrate kit (Vector Laboratories). The sections were then mounted on glass slides and coverslipped.

\section{c-Fos expression}

c-Fos was chosen as a candidate protein with which to measure the effects of CREB antisense on training-related protein expression. The $c$-fos gene has a CRE site in its promoter and is regulated by CREB (Impey et al. 2004). Also, c-Fos expression in the lateral and basolateral amygdala increases significantly after avoidance training (e.g., Radulovic et al. 1998; Savonenko et al. 1999; Holahan and White 2004). CREB antisense $(2 \mathrm{nmol} / 1 \mu \mathrm{L})$ was infused into one amygdala, and rOGN $(2 \mathrm{nmol} / 1 \mu \mathrm{L})$ was infused into the contralateral amygdala $6 \mathrm{~h}$ prior to inhibitory avoidance training $(0.5 \mathrm{~mA} / 1.5 \mathrm{sec})$. Rats $(N=5)$ were anesthetized $1.5 \mathrm{~h}$ later, and brain sections traversing the infusion sites were collected as described above. Sections to be analyzed were $\sim 100 \mu \mathrm{m}$ from the damage produced by the cannulae tracks. The sections were stored in a cryopreservative solution at $-20^{\circ} \mathrm{C}$ until c-Fos immunohistochemistry was performed. Free-floating sections were washed in $0.05 \mathrm{M}$ PBS, incubated in $1 \%$ hydrogen peroxide and $0.4 \%$ triton X, blocked with $3 \%$ goat serum, and incubated for 48 $\mathrm{h}$ in c-Fos primary antibody (1:5000 rabbit polyclonal; Santa Cruz, Inc.) at $4^{\circ} \mathrm{C}$. Sections were then washed in PBS, incubated for $1 \mathrm{~h}$ at room temperature in goat anti-rabbit secondary antibody (1:400; Santa Cruz, Inc.), and processed using the ABC Vectastain kit (Vector Laboratories), and c-Fos was stained with diaminobenzidine. The sections were then mounted on glass slides and coverslipped.

\section{Quantification of CREB, pCREB, and c-Fos immunoreactive cells}

Quantification of immunoreactive cells was based on methods previously described (Brown et al. 1998; Countryman and Gold 2007). Sections were imaged using a Leica DM 6000B/CTR6000 light microscope and a Leica DFC350 FX video camera, which was interfaced to an EP PC computer. Leica Application Suite software was used for image acquisition and NIH ImageJ software (Rasband 2006) for cell count quantification. A $40 \times$ objective was used to capture images and quantify cells in the amygdala. Each picture was enhanced by subtracting background, equalizing contrast, sharpening, and smoothing using standard software commands. Cell counts were determined using a particle range of 50 to 5000 pixels.

\section{Statistics}

In the microdialysis experiment, baseline release values for norepinephrine and acetylcholine were determined by averaging the content of the four microdialysis samples prior to training for each rat. The percent change from baseline was then calculated for the neurotransmitter content in each microdialysis sample. Mean absolute levels across treatment conditions were compared using Student's $t$-tests. Differences in percent change from baseline for norepinephrine and acetylcholine values across training 
and post-training samples within groups were performed using one-way repeated measures ANOVAs. Dunnett's post hoc tests were performed to determine differences from baseline for individual samples. The percent change in training and post-training release of norepinephrine and acetylcholine in the amygdala between control and CREB antisense groups was compared using two-way repeated measures ANOVAs, with treatment (control or CREB antisense) and time (one training and 13 consecutive posttraining samples) as the two grouping variables. Additionally, Bonferroni posttests compared differences in percent change in release of norepinephrine and acetylcholine in individual posttraining microdialysis samples between control and CREB antisense groups.

In the clenbuterol experiment, differences in 48-h latencies between groups that received intra-amygdala rOGN, CREB antisense, CREB antisense plus $1 \mathrm{ng}$ clenbuterol, and CREB antisense plus $10 \mathrm{ng}$ clenbuterol were analyzed using a one-way ANOVA. Bonferroni post-tests were performed to determine differences in retention latencies between individual groups. Differences in inhibitory avoidance retention latencies between intra-amygdala infusions of $10 \mathrm{ng}$ of clenbuterol and saline were analyzed using a Student's $t$-test.

\section{Acknowledgments}

This report was supported by research grants from the National Institute on Aging (AG07648) and the National Institute on Drug Abuse (DA016951 and DA024129). We thank Jamie R. Richards for her excellent assistance with the experiments described here.

\section{References}

Amaral, D.G., Price, J.L., Pitkänen, A., and Carmichael, S.T. 1992. Anatomical organization of the primate amygdaloid complex. In The amygdala: Neurobiological aspects of emotion, memory, and mental dysfunction (ed. J.P. Aggleton), pp. 1-66. Wiley-Liss, New York.

Aston-Jones, G. 2004. Locus coeruleus, A5 and A7 noradrenergic cell groups. In The rat nervous system, 3d ed. (ed. G. Paxinos), pp. 259-294. Elsevier Academic Press, San Diego.

Barco, A., Pittenger, C., and Kandel, E.R. 2003. CREB, memory enhancement and the treatment of memory disorders: Promises, pitfalls and prospects. Expert Opin. Ther. Targets 7: 101-114.

Berlau, D.J. and McGaugh, J.L. 2006. Enhancement of extinction memory consolidation: The role of the noradrenergic and GABAergic systems within the basolateral amygdala. Neurobiol. Learn. Mem. 86: $123-132$.

Bianchin, M., Mello e Souza, T., Medina, J.H., and Izquierdo, I. 1999. The amygdala is involved in the modulation of long-term memory, but not in working or short-term memory. Neurobiol. Learn. Mem. 71: $127-131$.

Bourtchuladze, R., Frenguelli, B., Blendy, J., Cioffi, D., Schutz, G., and Silva, A.J. 1994. Deficient long-term memory in mice with a targeted mutation of the cAMP-responsive element-binding protein. Cell 79: 59-68.

Brightwell, J.J., Smith, C.A., Countryman, R.A., Neve, R.L., and Colombo, P.J. 2005. Hippocampal overexpression of mutant CREB blocks long-term, but not short-term memory for a socially transmitted food preference. Learn. Mem. 12: 12-17.

Brown, H.E., Garcia, M.M., and Harlan, R.E. 1998. A two focal plane method for digital quantification of nuclear immunoreactivity in large brain areas using NIH-image software. Brain Res. Brain Res. Protoc. 2: 264-272.

Caine, S.B., Heinrichs, S.C., Coffin, V.L., and Koob, G.F. 1995. Effects of the dopamine D-1 antagonist SCH 23390 microinjected into the accumbens, amygdala or striatum on cocaine self-administration in the rat. Brain Res. 692: 47-56.

Canal, C.E., Chang, Q., and Gold, P.E. 2007. Amnesia produced by altered release of neurotransmitters after intra-amygdala injections of a protein synthesis inhibitor. Proc. Natl. Acad. Sci. 104: $12500-12505$.

Carlson, J. and Heimer, L. 1986. A correlated light and electron microscopic immunocytochemical study of cholinergic terminals and neurons in the rat amygdaloid body with special emphasis on the basolateral amygdaloid nucleus. J. Comp. Neurol. 244: 121-136.

Carlson, J., Zaborszky, L., and Heimer, L. 1985. Cholinergic projections form the basal forebrain to the basolateral amygdaloid complex: A combined retrograde fluorescent and immunohistochemical study. $J$. Comp. Neurol. 234: 155-167.

Chang, Q., Savage, L.M., and Gold, P.E. 2006. Microdialysis measures of functional increases in ACh release in the hippocampus with and without inclusion of acetylcholinesterase inhibitors in the perfusate. I. Neurochem. 97: 697-706.

Choi, K.-H., Whisler, K., Graham, D.L., and Self, D.W. 2006. Antisense-induced reduction in nucleus accumbens cyclic AMP response element binding protein attenuates cocaine reinforcement. Neuroscience 137: 373-383.

Colombo, P.J., Brightwell, J.J., and Countryman, R.A. 2003. Cognitive strategy-specific increases in phosphorylated cAMP response element-binding protein and c-Fos in the hippocampus and dorsal striatum. J. Neurosci. 23: 3547-3554.

Countryman, R.A. and Gold, P.E. 2007. Rapid forgetting of social transmission of food preferences in aged rats: Relationship to hippocampal CREB activation. Learn. Mem. 14: 350-358.

Countryman, R.A., Orlowski, J.D., Brightwell, J.J., Oskowitz, A.Z., and Colombo, P.J. 2005. CREB phosphorylation and c-Fos expression in the hippocampus of rats during acquisition and recall of a socially transmitted food preference. Hippocampus 15: 56-67.

Dash, P.K., Hochner, B., and Kandel, E.R. 1990. Injection of the cAMP-responsive element into the nucleus of Aplysia sensory neurons blocks long-term facilitation. Nature 345: 718-721.

Davies, M.F., Tsui, J., Flannery, J.A., Li, X., DeLorey, T.M., and Hoffman, B.B. 2004. Activation of $\alpha 2$ adrenergic receptors suppresses fear conditioning: Expression of c-Fos and phosphorylated CREB in mouse amygdala. Neuropsychopharmacology 29: 229-239.

Edeline, J.-M., Hars, B., Hennevin, E., and Cotillon, N. 2002. Muscimol diffusion after intracerebral microinjections: A reevaluation based on electrophysiological and autoradiographic quantifications. Neurobiol. Learn. Mem. 78: 100-124.

Ehrlich, G., Patinkin, D., Ginzberg, D., Zakut, H., Eckstein, F., and Soreq, H. 1994. Use of partially phosphorothioated "antisense" oligodeoxynucleotides for sequence-dependent modulation of hematopoiesis in culture. Antisense Res. Dev. 4: 173-183.

Ferry, B. and McGaugh, J.L. 1999. Clenbuterol administration into the basolateral amygdala post-training enhances retention in an inhibitory avoidance task. Neurobiol. Learn. Mem. 72: 8-12.

Florian, C., Mons, N., and Roullet, P. 2006. CREB antisense oligodeoxynucleotide administration into the dorsal hippocampal CA3 region impairs long- but not short-term spatial memory in mice. Learn. Mem. 13: 465-472.

Frankland, P.W., Josselyn, S.A., Anagnostaras, S.G., Kogan, J.H., Takahashi, E., and Silva, A.J. 2004. Consolidation of CS and US representations in associative fear conditioning. Hippocampus 14: $557-569$.

Gallagher, M. and Kapp, B.S. 1981. Effect of phentolamine administration into the amygdala complex of rats on time-dependent memory processes. Behav. Neural Biol. 31: 90-95.

Gallagher, M., Kapp, B.S., Musty, R.E., and Driscoll, P.A. 1977. Memory formation: Evidence for a specific neurochemical system in the amygdala. Science 198: 423-425.

Galvez, R., Mesches, M.H., and McGaugh, J.L. 1996. Norepinephrine release in the amygdala in response to footshock stimulation. Neurobiol. Learn. Mem. 66: 253-257.

Giles, R.V. and Tidd, D.M. 1992. Increased specificity for antisense oligodeoxynucleotide targeting of RNA cleavage by RNase H using chimeric methylphosphonodiester/phosphodiester structures. Nucleic Acids Res. 20: 763-770.

Gold, P.E. 2005. Glucose and age-related changes in memory. Neurobiol. Aging 26S: S60-S64.

Gold, P.E. 2006. The many faces of amnesia. Learn. Mem. 13: 506-514

Gold, P.E. 2008. Protein synthesis inhibition: Memory formation vs. amnesia. Neurobiol. Learn. Mem. 89: 201-211.

Gold, P.E. and van Buskirk, R.B. 1978a. Posttraining brain norepinephrine concentrations: Correlation with retention performance of avoidance training and with peripheral epinephrine modulation of memory processing. Behav. Biol. 23: 509-520.

Gold, P.E. and van Buskirk, R.B. 1978b. Effects of $\alpha$ - and $\beta$-adrenergic receptor antagonists on post-trial epinephrine modulation of memory: Relationship to post-training brain norepinephrine concentrations. Behav. Biol. 24: 168-184.

Greenwood, J.M. and Dragunow, M. 2002. Muscarinic receptor-mediated phosphorylation of cyclic AMP response element binding protein in human neuroblastoma cells. J. Neurochem. 82: 389-397.

Guzowski, J.F. and McGaugh, J.L. 1997. Antisense oligodeoxynucleotide-mediated disruption of hippocampal cAMP response element binding protein levels impairs consolidation of memory for water maze training. Proc. Natl. Acad. Sci. 94: $2693-2698$.

Guzowski, J.F., Lyford, G.L., Stevenson, G.D., Houston, F.P., McGaugh, J.L., Worley, P.F., and Barnes, C.A. 2000. Inhibition of activity-dependent Arc protein expression in the rat hippocampus impairs the maintenance of long-term potentiation and the 
consolidation of long-term memory. J. Neurosci. 20: 3993-4001.

Hajnal, A., Pthos, E.N., Lenard, L., and Hoebel, B.G. 1998. Effects of feeding and insulin on extracellular acetylcholine in the amygdala of freely moving rats. Brain Res. 785: 41-48.

Hatfield, T. and McGaugh, J.L. 1999. Norepinephrine infused into the basolateral amygdala posttraining enhances retention in a spatial water maze task. Neurobiol. Learn. Mem. 71: 232-239.

Hebb, M.O. and Robertson, H.A. 1997. End-capped antisense oligodeoxynucleotides effectively inhibit gene expression in vivo and offer a low-toxicity alternative to fully modified phosphorothioate oligodeoxynucleotides. Brain Res. Mol. Brain Res. 47: 223-228.

Holahan, M.R. and White, N.M. 2004. Amygdala c-Fos induction corresponds to unconditioned and conditioned aversive stimuli but not to freezing. Behav. Brain Res. 152: 109-120.

Impey, S., Mark, M., Villacres, E.C., Poser, S., Chavkin, C., and Storm D.R. 1996. Induction of CRE-mediated gene expression by stimuli that generate long-lasting LTP in area CA1 of the hippocampus. Neuron 16: 973-982.

Impey, S., Smith, D.M., Obrietan, K., Donahue, R., Wade, C., and Storm, D.R. 1998. Stimulation of cAMP response element (CRE)-mediated transcription during contextual learning. Nat. Neurosci. 1: 595-601.

Impey, S., McCorkle, S.R., Cha-Molstad, H., Dwyer, J.M., Yochum, G.S., Boss, J.M., McWeeney, S., Dunn, J.J., Mandel, G., and Goodman, R.H. 2004. Defining the CREB regulon: A genome-wide analysis of transcription factor regulatory regions. Cell 119: 1041-1054.

Izquierdo, I., da Cunha, C., Rosat, R., Jerusalinsky, D., Ferreira, M.B., and Medina, J.H. 1992. Neurotransmitter receptors involved in post-training memory processing by the amygdala, medial septum, and hippocampus of the rat. Behav. Neural Biol. 58: 16-26.

Jasnow, A.M., Shi, C., Israel, J.E., Davis, M., and Huhman, K.L. 2005. Memory of social defeat is facilitated by cAMP response element-binding protein overexpression in the amygdala. Behav. Neurosci. 119: 1125-1130.

Josselyn, S.A. and Nguyen, P.V. 2005. CREB, synapses and memory disorders: Past progress and future challenges. Curr. Drug Targets CNS Neurol. Disord. 4: 481-497.

Josselyn, S.A., Shi, C., Carlezon Jr., W.A., Neve, R.L., and Nestler, E.J. 2001. Long-term memory is facilitated by cAMP response element-binding protein overexpression in the amygdala. J. Neurosci. 21: 2404-2412.

Josselyn, S.A., Kida, S., and Silva, A.J. 2004. Inducible repression of CREB function disrupts amygdala-dependent memory. Neurobiol. Learn. Mem. 82: 159-163.

Kandel, E.R. 2001. The molecular biology of memory storage: A dialogue between genes and synapses. Science 294: 1030-1038.

Kurreck, J. 2003. Antisense technologies: Improvement through novel chemical modifications. Eur. J. Biochem. 270: 1628-1644.

LaLumiere, R.T. and McGaugh, J.L. 2005. Memory enhancement induced by post-training intrabasolateral amygdala infusions of $\beta$-adrenergic or muscarinic agonists requires activation of dopamine receptors: Involvement of right, but not left, basolateral amygdala. Learn. Mem. 12: 527-532.

Lamprecht, R., Hazvi, S., and Dudai, Y. 1997. cAMP response element-binding protein in the amygdala is required for long- but not short-term conditioned taste aversion memory. J. Neurosci. 17: 8443-8450.

Levin, A.A. 1999. A review of issues in the pharmacokinetics and toxicology of phosphorothioate antisense oligonucleotides. Biochim. Biophys. Acta 1489: 69-84.

Liang, K.C., Juler, R.G., and McGaugh, J.L. 1986. Modulating effects of posttraining epinephrine on memory: Involvement of the amygdala noradrenergic system. Brain Res. 368: 125-133.

Liang, K.C., McGaugh, J.L., and Yao, H.Y. 1990. Involvement of amygdala pathways in the influence of post-training intra-amygdala norepinephrine and peripheral epinephrine on memory storage. Brain Res. 508: 225-233.

Liang, K.C., Chen, L.L., and Huang, T.E. 1995. The role of amygdala norepinephrine in memory formation: Involvement in the memory enhancing effect of peripheral epinephrine. Chin. J. Physiol. 38: 81-91.

Mark, G.P., Rada, P.V., and Shors, T.J. 1996. Inescapable stress enhances extracellular acetylcholine in the rat hippocampus and prefrontal cortex but not the nucleus accumbens or amygdala. Neuroscience 74: $767-774$

McGaugh, J.L. 2004. The amygdala modulates the consolidation of memories of emotionally arousing experiences. Annu. Rev. Neurosci. 27: $1-28$.

McIntyre, C.K., Hatfield, T., and McGaugh, J.L. 2002. Amygdala norepinephrine levels after training predict inhibitory avoidance retention performance in rats. Eur. J. Neurosci. 16: 1223-1226.

McIntyre, C.K., Marriott, L.K., and Gold, P.E. 2003a. Cooperation between memory systems: Acetylcholine release in the amygdala correlates positively with performance on a hippocampus dependent task. Behav. Neurosci. 117: 320-326.

McIntyre, C.K., Power, A.E., Roozendaal, B., and McGaugh, J.L. 2003b. Role of the basolateral amygdala in memory consolidation. Ann. N. Y. Acad. Sci. 985: 273-293.

McIntyre, C.K., Miyashita, T., Setlow, B., Marjon, K.D., Steward, O., Guzowski, J.F., and McGaugh, J.L. 2005. Memory-influencing intra-basolateral amygdala drug infusions modulate expression of Arc protein in the hippocampus. Proc. Natl. Acad. Sci. 102: 10718-10723.

Miranda, M.I., LaLumiere, R.T., Buen, T.V., Bermudez-Rattoni, F., and McGaugh, J.L. 2003. Blockade of noradrenergic receptors in the basolateral amygdala impairs taste memory. Eur. J. Neurosci. 18: $2605-2610$.

Ou, L.-C. and Gean, P.-W. 2007. Transcriptional regulation of brain-derived neurotrophic factor in the amygdala during consolidation of fear memory. Mol. Pharmacol. 72: 350-358.

Paxinos, G. and Watson, C. 2005. The rat brain in stereotaxic coordinates, 5 th ed. Elsevier, Burlington, MA.

Paz, R., Pelletier, J.G., Bauer, E.P., and Pare, D. 2006. Emotional enhancement of memory via amygdala-driven facilitation of rhinal interactions. Nat. Neurosci. 9: 1321-1329.

Pittenger, C., Huang, Y.Y., Paletzki, R.F., Bourtchouladze, R., Scanlin, H., Vronskaya, S., and Kandel, E.R. 2002. Reversible inhibition of CREB/ATF transcription factors in region CA1 of the dorsal hippocampus disrupts hippocampus-dependent spatial memory. Neuron 34: 447-462.

Power, A.E., McIntyre, C.K., Litmanovich, A., and McGaugh, J.L. 2003a. Cholinergic modulation of memory in the basolateral amygdala involves activation of both M1 and M2 receptors. Behav. Pharmacol. 14: $207-213$.

Power, A.E., Vazdarjanova, A., and McGaugh, J.L. 2003b. Muscarinic cholinergic influences in memory consolidation. Neurobiol. Learn. Mem. 80: 178-193.

Qiao, L., Han, S.L., Fang, Y., Park, J.S., Gupta, S., Gilfor, D., Amorino, G., Valerie, K., Sealy, L., Engelhardt, J.F., et al. 2003. Bile acid regulation of C/EBP $\beta$, CREB, and c-Jun function, via the extracellular signal-regulated kinase and c-Jun $\mathrm{NH}_{2}$-teminal kinase pathways, modulates the apoptotic response of hepatocytes. Mol. Cell. Biol. 23: 3052-3066.

Radulovic, J., Kammermeier, J., and Spiess, J. 1998. Relationship between fos production and classical fear conditioning: Effects of novelty, latent inhibition, and unconditioned stimulus preexposure. J. Neurosci. 18: 7452-7461.

Raiteri, M. 2006. Functional pharmacology in human brain. Pharmacol. Rev. 58: 162-193.

Raiteri, M. 2008. Presynaptic metabotropic glutamate and $\mathrm{GABA}_{\mathrm{B}}$ receptors. In Handbook of experimental pharmacology (eds. T.C. Südhof and K. Starke), pp. 373-407. SpringerLink, Berlin.

Rasband, W.S. 2006. ImageJ. U.S. National Institutes of Health, Bethesda, MD.

Roozendaal, B., Barsegyan, A., and Lee, S. 2008. Adrenal stress hormones, amygdala, activation, and memory for emotionally arousing experiences. Prog. Brain Res. 167: 79-97.

Saha, S. and Datta, S. 2005. Two-way active avoidance training-specific increases in phosphorylated cAMP response element-binding protein in the dorsal hippocampus, amygdala, and hypothalamus. Eur. J. Neurosci. 21: 3403-3414.

Salinas, J.A., Introini-Collison, I.B., Dalmaz, C., and McGaugh, J.L. 1997. Posttraining intra-amygdala infusions of oxotremorine and propranolol modulate storage of memory for reductions in reward magnitude. Neurobiol. Learn. Mem. 68: 51-59.

Savonenko, A., Filipkowski, R.K., Werka, T., Zielinski, K., and Kaczmarek, L. 1999. Defensive conditioning-related functional heterogeneity among nuclei of the rat amygdala revealed by c-Fos mapping. Neuroscience 94: 723-733.

Schafe, G.E., Nader, K., Blair, H.T., and LeDoux, J.E. 2001. Memory consolidation of Pavlovian fear conditioning: A cellular and molecular perspective. Trends Neurosci. 24: 540-546.

Schulz, S., Siemer, H., Krug, M., and Hollt, V. 1999. Direct evidence for diphasic cAMP responsive element-binding protein phosphorylation during long-term potentiation in the rat dentate gyrus in vivo. $J$. Neurosci. 19: 5683-5692.

Selcher, J.C., Weeber, E.J., Varga, A.W., Sweatt, J.D., and Swank, M. 2002. Protein kinase signal transduction cascades in mammalian associative conditioning. Neuroscientist 8: 122-131.

Silva, A.J., Kogan, J.H., Frankland, P.W., and Kida, S. 1998. CREB and memory. Annu. Rev. Neurosci. 21: 127-148.

Stanciu, M., Radulovic, J., and Spiess, J. 2001. Phosphorylated cAMP response element binding protein in the mouse brain after fear conditioning: Relationship to Fos production. Brain Res. Mol. Brain 
Res. 94: $15-24$.

Vazdarjanova, A. and McGaugh, J.L. 1999. Basolateral amygdala is involved in modulating consolidation of memory for classical fear conditioning. J. Neurosci. 19: 6615-6622.

Wallace, D.M., Magnuson, D.J., and Gray, T.S. 1992. Organization of amygdaloid projections to brainstem dopaminergic, noradrenergic, and adrenergic cell groups in the rat. Brain Res. Bull. 28: 447-454.

Westerink, B.H.C. and Timmerman, W. 1999. Do neurotransmitters sampled by brain microdialysis reflect functional release? Anal. Chim. Acta 379: 263-274.

Williams, C.L., Men, D., Clayton, E.C., and Gold, P.E. 1998

Norepinephrine release in the amygdala after systemic injection of epinephrine or escapable footshock: Contribution of the nucleus of the solitary tract. Behav. Neurosci. 112: 1414-1422.

Woolf, N.J. and Butcher, L.L. 1982. Cholinergic projections to the basolateral amygdala: A combined Evans blue and acetylcholinesterase analysis. Brain Res. Bull. 8: 751-763.

Yin, J.C.P. and Tully, T. 1996. CREB and the formation of long-term memory. Curr. Opin. Neurobiol. 6: 264-268.

Yin, J.C.P., Wallach, S., Del Vecchio, M., Wilder, E.L., Zhou, H., Quinn,
W.G., and Tully, T. 1994. Induction of a dominant negative CREB transgene specifically blocks long-term memory in Drosophila. Cell 79: $49-58$

Yin, J.C.P., Del Vecchio, M., Zhou, H., and Tully, T. 1995. CREB as a memory modulator: Induced expression of a dCREB2 activator isoform enhances long-term memory in Drosophila. Cell 81: 107-115.

Yuan, Q., Harley, C.W., Bruce, J.C., Darby-King, A., and McLean, J.H. 2000. Isoproterenol increases CREB phosphorylation and olfactory nerve-evoked potentials in normal and 5-HT-depleted olfactory bulbs in rat pups only at doses that produce odor preference learning. Learn. Mem. 7: 413-421.

Zhang, J.J., Okutani, F., Inoue, S., and Kaba, H. 2003. Activation of the cyclic AMP response element-binding protein signaling pathway in the olfactory bulb is required for the acquisition of olfactory aversive learning in young rats. Neuroscience 117: 707-713.

Received January 13, 2008; accepted in revised form July 5, 2008. 


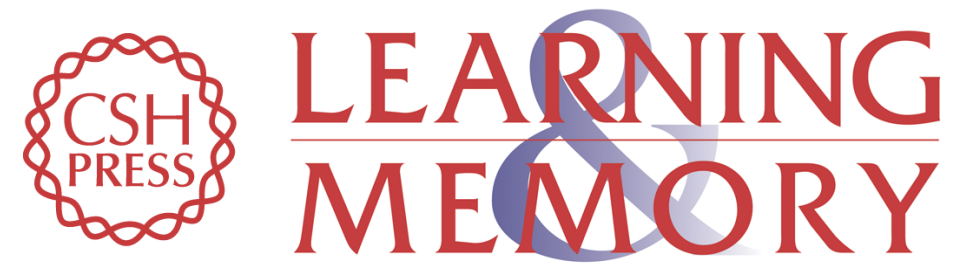

\section{Intra-amygdala injections of CREB antisense impair inhibitory avoidance memory: Role of norepinephrine and acetylcholine}

Clinton E. Canal, Qing Chang and Paul E. Gold

Learn. Mem. 2008, 15:

Access the most recent version at doi:10.1101/lm.904308

References This article cites 88 articles, 21 of which can be accessed free at: http://learnmem.cshlp.org/content/15/9/677.full.html\#ref-list-1

License

Email Alerting Receive free email alerts when new articles cite this article - sign up in the box at the Service top right corner of the article or click here. 